\title{
UCCE helps community coalitions reduce childhood overweight
}

\author{
by Gloria B. Espinosa-Hall, Diane Metz, \\ Margaret Johns, Dorothy Smith, \\ Patricia B. Crawford, Kirstin Siemering \\ and Joanne Ikeda
}

In 2001, UC Cooperative Extension nutrition specialists with the Center for Weight and Health introduced the Children and Weight: What Communities Can Do About It project, with the goal of reducing the prevalence of pediatric overweight. This project was designed to facilitate the formation of community coalitions, and to educate and empower them to improve or create environments that foster healthy lifestyles in children and their families at the local level. The project has been implemented in 13 California counties and by groups across the country. The "Spectrum of Prevention" is featured as a way to address the problem of pediatric overweight from multiple levels, ranging from educating individuals and providers to advocating for systemic and environmental change. Shasta CAN in Shasta County, the Solano County Children and Weight Coalition and the Kern County Childhood Overweight Coalition are presented as models of how coalitions can creatively plan and implement activities across the spectrum.

IN the late 1990s, UC Cooperative Extension nutrition specialists and Experiment Station faculty began to notice a dramatic increase in overweight children in California. Pediatric overweight had become "epidemic": its prevalence had tripled from $5 \%$ to $15 \%$ over the preceding 30 years and rates were significantly higher for minority children, especially those from low-income families (fig. 1) (Troiano and Flegal 1998). Overweight children

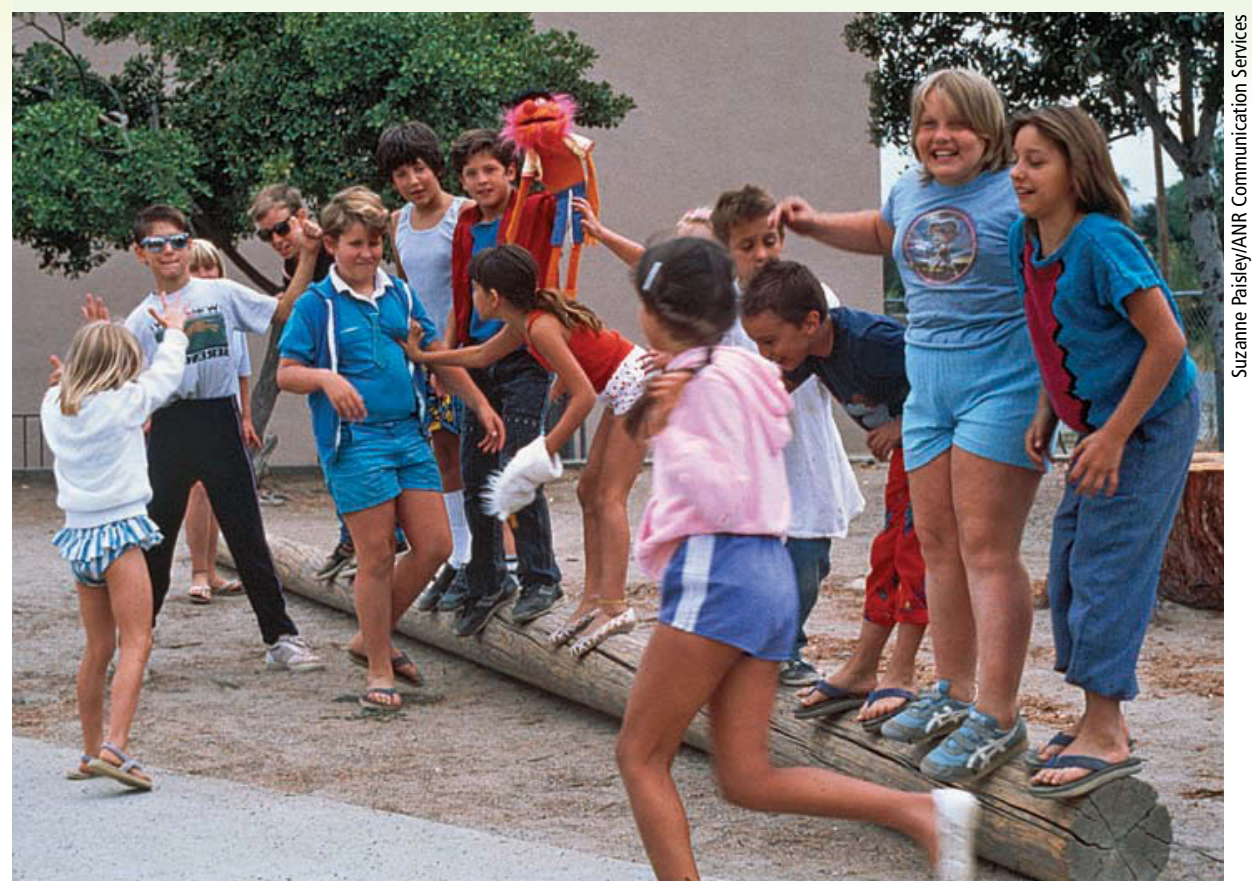

Children have been gaining weight in recent decades due to factors such as the school environment, community design and safety concerns that discourage outdoor play, and diets increasingly heavy in sugar and fat.

as young as 6 years old were receiving diagnoses of hypertension, hyperlipidemia (high serum cholesterol or high blood triglycerides) and joint problems. In addition, the risk of chronic disease later in life was increased for these children. California children born in 2000 had an estimated one in three chance of developing type 2 diabetes during their lifetimes (Fagot-Campagna et al. 2000).

Specialists and faculty realized that one of the major factors contributing to this environment was a rapidly changing environment. Schools in California were selling foods of poor nutritional quality to children to raise funds for school programs, activities and events. Daily physical education was reduced or eliminated, since it was viewed as less important than classroom instruction (AAHPERD 2005). With the new emphasis on test scores, there was little incentive to teach children how to care for their physical, social and emotional health. In addition, fewer children were walking and bicycling to school (CDC 2006).

Outside of school, children's environments had also changed. Many communities lacked sidewalks, but even in places with sidewalks, parents worried about safety issues related to children walking or riding alone. Too many urban parks had become places where the homeless resided or where drugs were sold. Low-income neighborhoods lacked supermarkets that stocked a variety of reasonably priced fresh produce, but had many liquor stores and fast-food restaurants. Few children were spending even 1 hour playing actively, and the average child spent over 4 hours a day in front of the TV screen (Roberts and Foehr 2004). Television commercials emphasized the desirability of soft drinks, sugar-coated cereals and eating at fast-food restaurants. The advertising industry was effective at marketing high-sugar and high-fat foods to children: by the late 1990s, nearly a third of the calorie intake of the average child in this country came from foods of poor nutrient density (Kant 2003).

The number of children and families affected by these societal, cultural and familial changes was so great that it was felt that an individual education approach (one-on-one counseling for each person or family at risk) would overwhelm the capacity of our health 
education system. Recognizing that no one group, agency or organization was going to be able to reverse the environmental trends underlying the rise in overweight children, UC nutrition specialists and faculty agreed that the only way to deal with the problem of pediatric overweight was through a community organizing approach that focused on environmental change. The formalization of such "bottom-up" community involvement in addressing health problems has been driven by past failings of "top-down" approaches (Zakocs and Edwards 2006).

\section{Forming community coalitions}

The development of community coalitions has become a defining approach to addressing social problems over the last decade (Chavis 2001). A coalition or alliance is formed when a group of individuals or organizations decides to work together to achieve mutually agreed-upon goals. Community coalitions bring together partners with diverse interests but the common goal of wanting to address a problem that is having a detrimental impact on community members. Each partner contributes resources that mobilize and focus on resolving the problem. These alliances have great potential for transforming communities because they can engage different segments of the community to develop the capacity to achieve a healthier environment.

The "Children and Weight: What Communities Can Do About It" project began with a series of meetings conducted by county UC Cooperative Extension nutrition, family and consumer science advisors. After launching the project in a statewide meeting held Nov. 17, 1999, local Cooperative Extension staff returned to their communities to conduct focus groups. The purpose of these groups was to assess community needs and perceptions of the problem of increasing pediatric overweight, and to begin to build local coalitions for future action. Eight focus groups were held in urban, suburban and rural communities in Northern and Southern California, and the Central Valley. The advisors asked representatives of various community agencies and institutions to brainstorm about how their community environment might be contributing to pediatric overweight and the changes that they would like to accomplish. Since this was a newly publicized health problem, there was a great deal of interest, and about 100 people attended the meetings.

Although enthusiasm for change was high, many individuals were pessimistic about the possibility of actually making a difference. In most cases, participants felt overextended and worried about the time and energy it would take. Since many were entrenched in the bureaucratic structures of their organizations, they did not feel they had the power and influence to effect change. However, when the possibility of forming an alliance that would include key community decision-makers and leaders was suggested, the participants were more enthusiastic.

Although there were numerous commonalities - such as the need to promote physical activity and provide consistent, accurate health information - these meetings suggested that there was no universal item among communities that they wanted to change. Each community identified its own unique set of problems as well as potential changes that its members felt were important. However, we identified a need to help communities prioritize and develop action plans to accomplish their goals. There was also a need to educate coalition members about the issues surrounding pediatric overweight so their efforts would focus on effective changes to address this problem.

\section{Resources for starting coalitions}

Based on these meetings, specialists and advisors determined that resources were needed to facilitate the formation, education and functioning of community coalitions. While the overall goal was to reduce the prevalence of childhood overweight in California, this tool was also designed to mobilize communities to create opportunities for children to eat nutrient-dense food such as fruits, vegetables and whole grains, and to become more physically active. These resources were developed and packaged as Children and Weight: What Communities Can Do, a kit that included: (1) a "how to" notebook with advice on forming a coalition; (2) templates for notices and agendas for meetings; (3) educational presentations on various aspects of pediatric overweight to be used at meetings; and (4) a decisionmaking process to implement over the course of five meetings. In addition, specialists made a videotape featuring coalitions in California that had accomplished environmental changes in community settings.

The resource materials were based

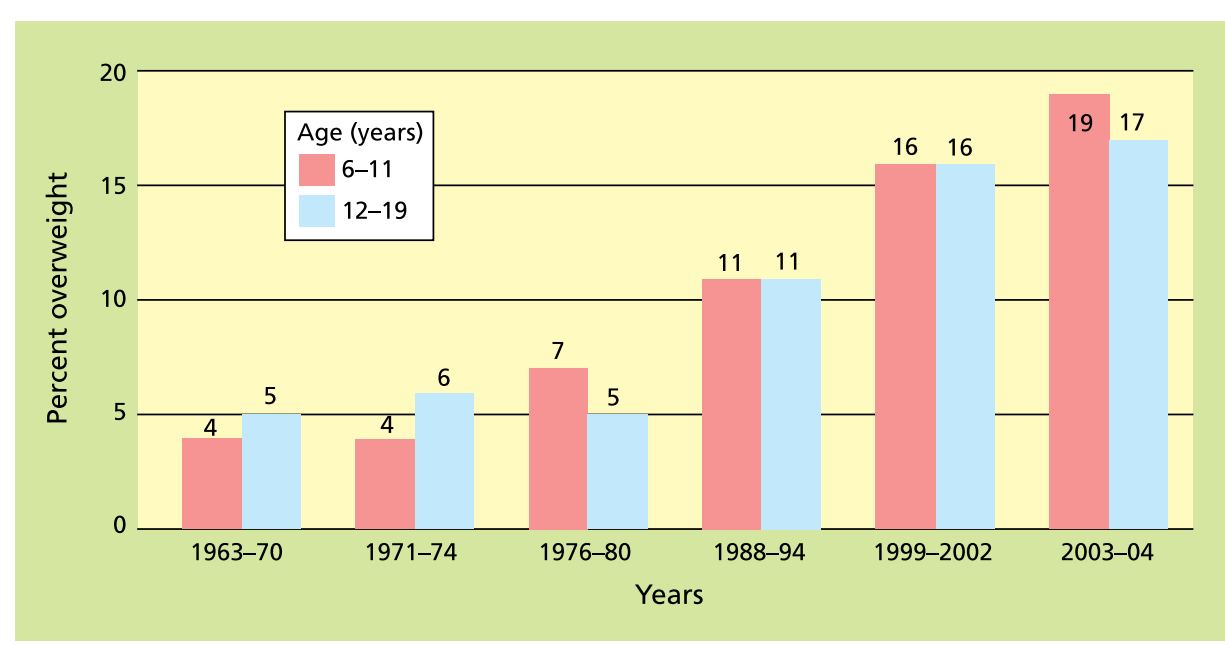

Fig. 1. Prevalence of overweight among U.S. children and adolescents ages 6-19 years (excludes pregnant women starting with 1971-1974 data). Overweight is a BMI greater than or equal to the 95th percentile for the child's age and sex. Source: NCHS 2007. 


\section{Spectrum of Prevention}

on a framework for addressing complex public-health problems called the "Spectrum of Prevention" (Cohen and Smith 1999). Originally developed by Larry Cohen when he was director of the Contra Costa County Health Services Prevention Program, the Spectrum of Prevention identifies multiple levels of intervention, and encourages coalitions to move beyond the perception that preventing a health problem is solely about teaching individuals to adopt healthier behaviors. Instead, this approach is designed to yield a more comprehensive understanding of prevention via six strategy development levels, extending from the individual to the government (fig. 2) (Cohen and Smith 1999).

\section{Children and Weight coalitions}

Between 2001 and 2005, county Cooperative Extension nutrition, family and consumer science advisors facilitated the formation of Children and Weight coalitions in 13 California communities (table 1). A 2004 survey of members of these coalitions found that they used multilevel strategies to create environments that support healthier lifestyles for children and their parents, including:

(1) Promoting community education and awareness using local newspapers, radio and television stations.

(2) Providing continuing medical education on all aspects of pediatric overweight for health professionals.

(3) Identifying treatment and intervention programs available in the community and supporting the expansion of these services.

(4) Sponsoring events for children and parents that promote the enjoyment of eating nutrient-dense foods and being physically active.

(5) Advocating for changes in the food sold in school vending machines and snack bars.

(6) Emphasizing the link between health and academic achievement so that schools recognize the importance of physical education and comprehensive school-health programs.

(7) Improving the safety of and access to community recreation facilities

$$
\begin{aligned}
& \text { Strengthening individual } \\
& \text { knowledge and skills }
\end{aligned}
$$

Promoting

community education

\section{Educating providers}

Fostering coalitions

and networks

Changing
organizational practices

Influencing

policy and legislation

\section{Enhance individual capacity}

Reach groups with

information and resources

Inform providers who
influence others

Convene groups and

individuals for greater impact

Adapt regulations and shape norms

Develop strategies to change laws and policies

\section{Fig. 2. Source: Cohen and Smith 1999; www.preventioninstitute.org.}

as well as the expansion of recreational opportunities for families.

(8) Encouraging children to walk or ride their bikes to school through the establishment of "walking school buses" and parent "corner" monitors along routes to schools.

The following three case studies from the 13 coalitions demonstrate the unique and varied approaches taken by community coalitions to reduce the prevalence of pediatric overweight in California.

\section{Shasta CAN}

The Shasta County Coalition for Activity and Nutrition (Shasta CAN) was started in 1999 by a group of local dietitians who were alarmed about the epidemic of childhood overweight. In summer 2001, the group's leader and the county's newly hired UC Cooperative Extension nutrition advisor attended a training hosted by the UC Berkeley Center for Weight and Health training on the Children and Weight program.

Their immediate goal following the training was to expand the coali- tion by recruiting additional partners from local agencies. Members visited schools to educate teachers and administrators about the increasing prevalence of childhood overweight and its consequences. The group sponsored a Children and Weight Conference, featuring Shasta County's health officer and a UC Berkeley nutrition specialist. To serve as the basis for Shasta CAN's strategic plan, conference attendees selected three goals they would like to see accomplished in their community.

Shasta CAN served as a countywide venue for planning, coordinating, delivering and evaluating nutrition and physical activity efforts. By pooling resources, coalition members reached larger audiences with programs that have greater impact on lifestyle behaviors.

In Shasta County, entire schools have participated in "Nutrition Decathlon" events, where children answer nutrition trivia questions in exchange for tickets to participate in physical activities that involve a fruit or a vegetable, such as the carrot hop, coconut bowling and potato-sack races. Thousands of students use pedometers to track the number of 
steps they take in a day. Many more take the "Nutrition and Physical Activity Challenge" by eating at least 5 cups of fruits and vegetables and being physically active for at least 1 hour each day.

Shasta CAN's community education efforts have focused primarily on "LeanN-Green Day," held annually in March (National Nutrition Month), and the "5-A-Day Challenge" held annually in September. Thousands of residents are exposed to nutrition and physical activity messages through mass media campaigns, fairs and coalition-sponsored community walks. After Lean-N-Green Day in $2005,72 \%$ of participants surveyed by the coalition reported that the event influenced their level of commitment to physical activity and their intake of fruits and vegetables.

Coalition members have educated teachers, food-service staff, health professionals, school board members, and members of the city council and county board of supervisors on their role in promoting and supporting a healthy environment for children and families. Even before the Federal Child Nutrition and WIC Reauthorization Act of 2004 made it mandatory for every school district to create a local wellness policy (CBO 2004), several Shasta County schools had started making changes in order to create a healthier school environment. Some schools started offering low-sugar, low-fat snacks, while others limited the frequency of selling sweets for fundraisers or started offering healthier food choices during sporting events. Some schools developed policies banning the sale of soft drinks and other highly sugared beverages. One school district adopted a policy that healthy foods and beverages should be available wherever food is offered or sold within the district. As a result of coalition members' involvement in the promotion and education of healthy school environments, several members have been invited to help form local wellness-policy committees.

In addition, some agencies in Shasta County have initiated organizational changes that contribute to improved employee health, such as offering
County (no. members)

\section{Contact}

Amador/Calaveras (21)

Dorothy Smith

DorSmith@ucdavis.edu

Contra Costa (20)

Charlotte Dickson

cdickson@hsd.cccounty.us

(925) 313-6217

Kern (15)

Margaret Johns

MCJohns@ucdavis.edu

Marin (20)

Jane Chin Young

JChin@ucdavis.edu

San Diego (58)

Beverly Tuzin

contact@ccwsd.org

(619) 692-8808

San Joaquin (25)

Anna Martin

ACMartin@ucdavis.edu

Santa Barbara (25)

Christy Schuerch

Christy@sbclinics.com

(805) $963-8566 \times 221$

Santa Clara (50)

Maria Giovanni

MEGiovanni@ucdavis.edu

Shasta (25)

Sherrie Brookes

sbrookes@co.shasta.ca.us

Solano (70)

Diane L. Metz

DLMetz@ucdavis.edu

Sonoma (32)

Wanda Tapia

wCTapia@ucdavis.edu

Trinity (10)

Eileen Stocum

estocum@trinitycounty.org

Yolo (25)

Maryfrances $E$. Collins

Maryfrances. Collins

@yolocounty.org

(530) 666-8662
Mission/goal Projects

Connect community resources into a common basket

- Hunger survey

- Cross County Health Challenge

Advocate and promote healthy lifestyles and environments that improve nutrition and physical activity for children and families

Improve the health of children and their families through the prevention of weight problems and related chronic diseases

Improve the health of Marin County in the next decade

- Healthy snack activities at high schools

- Middle school students as leaders

- Nutrition and Health Educational Theatre

Prevent childhood overweight by addressing its complex contributing factors

- School food and fitness summits - Conference for health professionals

- Toolkit for School Board Advocacy and Practice Management

Promote environmental and policy changes that facilitate healthy lifestyles for San Joaquin County children and their families

Improve the health of youth and their families; prevent chronic disease and promote healthy weight

Improve the health of children and their families through strategies that address weight problems and chronic diseases

Empower the people of Shasta County to make positive food choices and to be more physically active

- National Walk-to-School Day

- "Active for Life" workplace program

- Collaborate to reduce hunger and food insecurity

- Portion-size education

- Expand healthy food choices in youth environments

- Increase physical activity among youth

- Child-feeding trainings

- School nutrition and physical activity

- Policy changes

- Treatment program for overweight children

- School nutrition and physical activity

- Treatment program for overweight children

- Professional development conferences

- Pedometer program

Improve the health and well-being of children and their families by creating an environment that promotes healthy lifestyles

- Forums for countywide strategic plan

- Walk or bike to school event

- Healthy Eating Active Living (HEAL) initiative (Kaiser grant); workshops for various groups

Improve the health of children and their families through the prevention of chronic disease and weight problems

- Seminar on body image

- Community resources for families

- School food policy

- Farm to school

Improve the health of children and families through the education and promotion of good nutrition and physical activity

- School nutrition and physical activity education

- School food-service trainings

- Annual Children's Festival

- TV Turnoff Week

Create environments that

physical activity in Yolo County
- Develop strategic plan 
UC Cooperative Extension nutrition specialists developed a training kit with a variety of materials for helping communities form coalitions. To order, go to: http://anrcatalog. ucdavis.edu.

nutrient-dense refreshments like yogurt, fruit and nuts at staff meetings. Luncheon meetings have a greater variety of vegetables and lower fat dishes, and sodas have been replaced by water and $100 \%$ fruit juice. Employees are encouraged to participate in walking groups during breaks and lunchtime.

Another important development in Shasta County is the formation of a coalition called Healthy Shasta, which has the primary goal of working at a higher level of the Spectrum of Prevention. This coalition has enlisted the support of county officials, CEOs and department heads, to concentrate in seeking funds and developing countywide policies and environmental changes that support the establishment and sustainability of a healthy community.

\section{Solano County coalition}

In 2001, several Solano County Health Department professionals formed a group to promote lifestyle changes that would encourage healthy weights for children. Following training at the UC Berkeley Center for Weight and Health, the UC Cooperative Extension nutrition, family and consumer science advisor joined the planning team from the Solano County-based coalition. The group agreed to pilot-test the Children and Weight: What Communities Can Do curriculum that had been introduced at the U.C. Center for Weight and Health trainings. In November 2001, 40 people attended the first meeting of the Children and Weight Coalition of Solano County (CWCSC). This coalition met monthly during its first year, working its way through the coalitionbuilding curriculum, recruiting members and making suggested changes to the curriculum.

In October 2002, CWCSC sponsored a countywide forum attended by more than 50 individuals, including representatives of county and city agencies, health departments and schools from

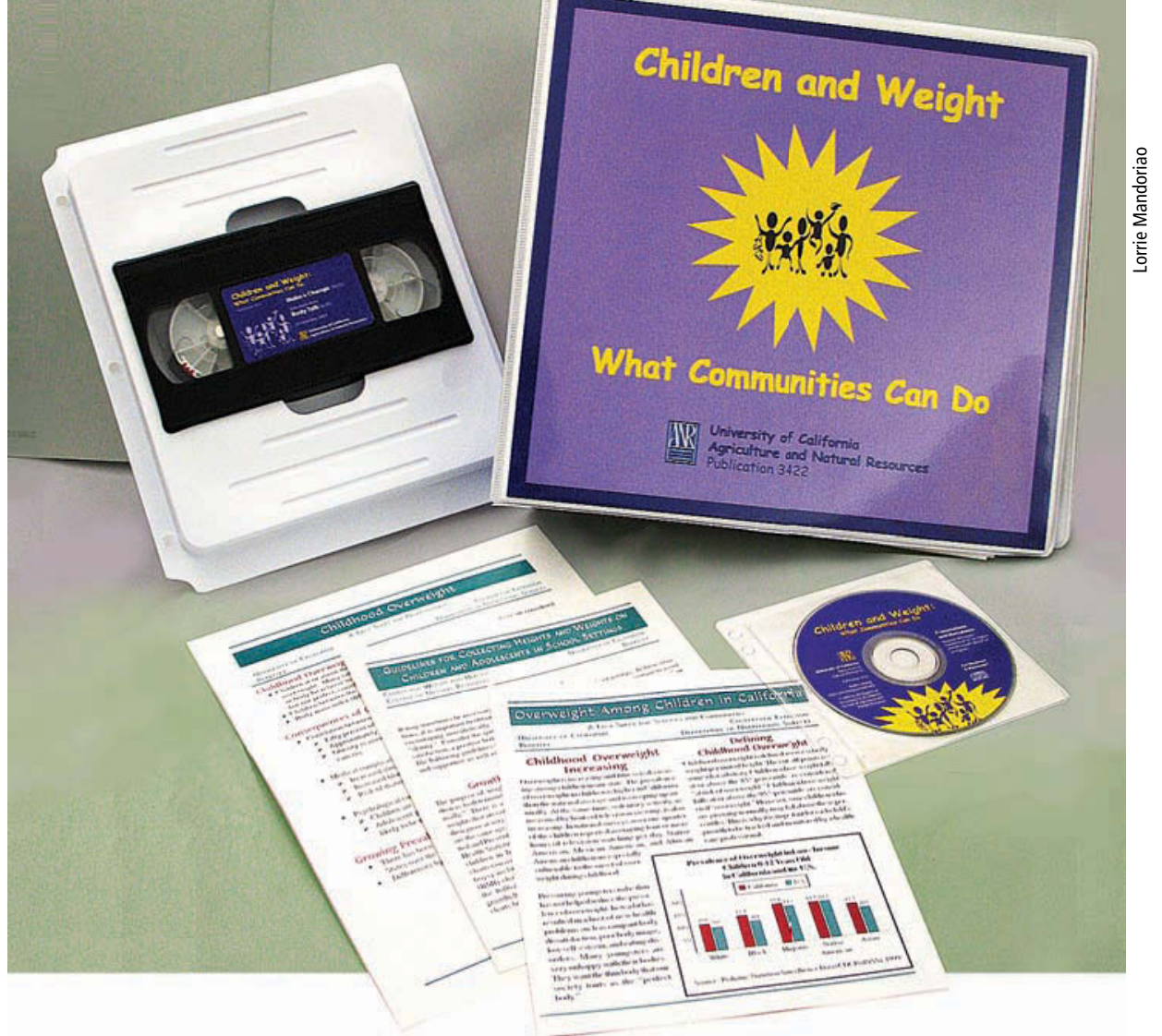

each of the county's six cities. Funds were secured through The California Endowment and local organizations, which enabled the coalition to convene community-based forums in Benicia, Dixon, Fairfield-Suisun, Rio Vista, Vacaville and Vallejo, as well as one for educators and another for health professionals. By December 2003, more than 400 people had attended these eight forums. The data gathered was tabulated and used to create the coalition's strategic plan. The project funds also allowed the group to test and design appropriate social marketing tools and develop the coalition's Web site (www.cwcsc. com). In 2004, CWCSC finalized its strategic plan, published and distributed it throughout the county, and presented it to the board of supervisors, where it was adopted.

Based on the plan, the group formed teams to coordinate events such as "Walk to School Day," which was offered in five of the six Solano County cities in fall 2004. Kaiser Permanente and North Bay Health Care provided funds for healthful food and activity incentives such as water bottles and wristband whistles to encourage more physical activity.

In late 2004, CWCSC received funds from Kaiser Permanente's Healthy Eating Active Living (HEAL) initiative. At a planning retreat in March 2005, members decided that these funds would be used to carry out communitybased projects promoting childhood health. Community teams were encouraged to apply for mini-grants of $\$ 1,000$, and four projects were funded:

(1) In Benicia, Robert Semple Elementary School purchased Sports, Play and Active Recreation for Kids (SPARK) equipment to promote physical activity.

(2) In Dixon, Silveyville Primary School conducted education classes on gardening, nutrition and physical activity for new immigrant parents.

(3) Child Start of Napa-Solano trained 46 Head Start teachers to use the SPARK curriculum when doing physical activity with preschoolers.

(4) Vallejo City Unified School District Student Health Services supported Walk to School activities reaching more than 350 children and adults.

Another CWCSC project using HEAL funds provided nutrition education to 20 parent-child teams in Fairfield, where lifestyle and health promotion information was shared, and participants prepared healthful meals and snacks. In addition, CWCSC used HEAL funds to offer Smart Moves workshops in Fairfield and Vallejo targeting day-care and after-school child-care providers. These workshops provide instruction on easy ways to 


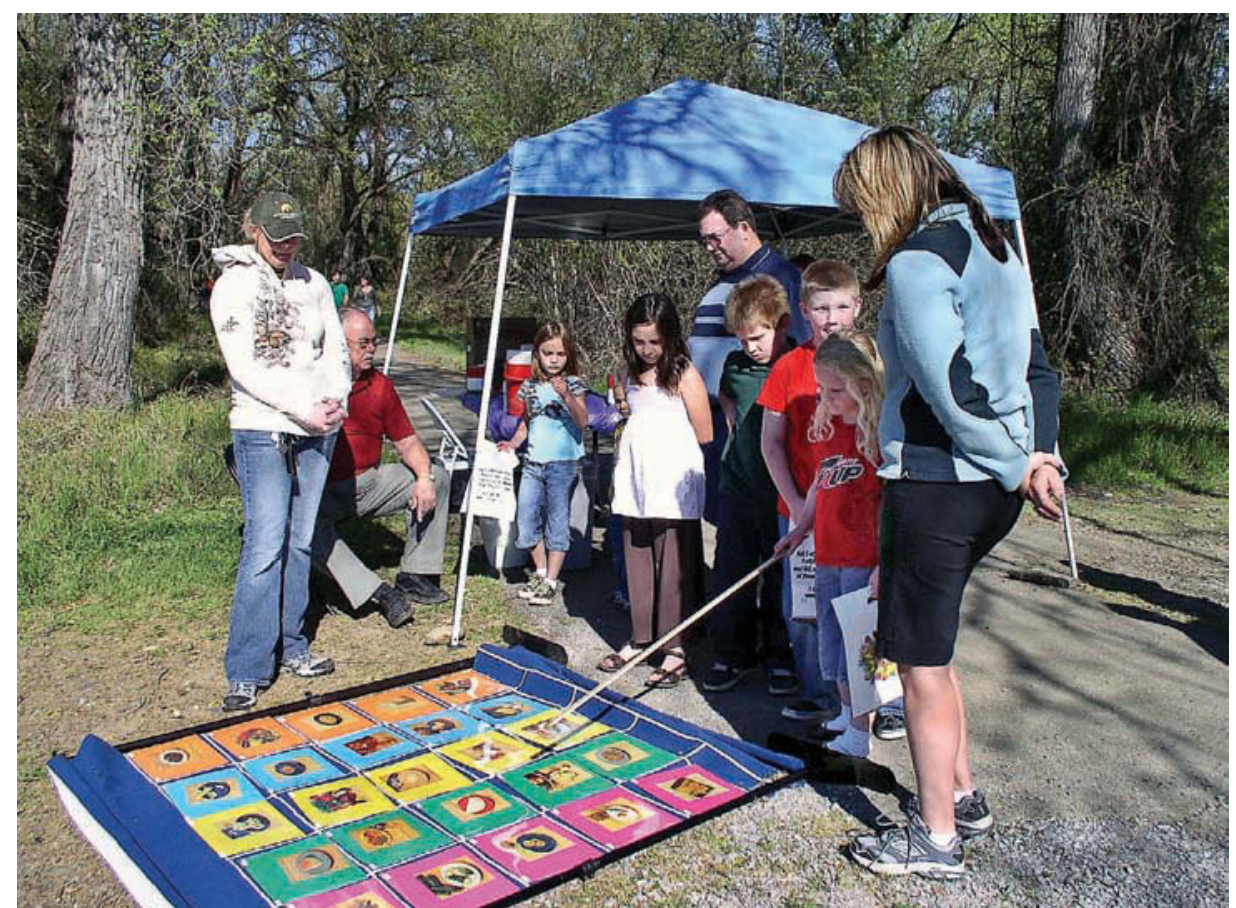

incorporate movement and increase the physical activity for children. More than 65 child-care providers attended the first round of workshops held in November 2005, and two more workshops were held in Vacaville and Vallejo in March 2006 to accommodate 35 providers on the waiting list.

Most cities in Solano County continue to carry out annual Walk to School events. Cooking classes for parents are offered in Dixon, soda machines at schools throughout Solano County now offer water and lowersugar beverages, and several school districts now offer more nutritious foods and portions in their cafeterias.

CWCSC has also worked to promote local agriculture. Solano County's population has more than doubled in the past 20 years, now exceeding 425,000 residents, mostly in urban areas. With such growth, many residents do not realize that agriculture remains one of the county's largest industries. The Food and Nutrition Coalition, an offshoot of CWCSC, has developed companion activities with support from the food banks of Contra Costa and Solano counties, and the Solano County Department of Health and Social Services. Both coalitions promote eating local produce and foods (such as whole grains and beans) by working with grower associations and farmers' markets.
CWCSC distributes "Solano Grown" flyers to promote the purchase of locally grown foods directly from farmer food stands in the county. The coalition has also found that using locally grown food in demonstrations and cooking activities piques the interest of participants. Increasingly, consumers want to know where their food is grown and how fresh it is; meanwhile, working with growers enables the agricultural community to see more clearly the connection between health and the products they produce and sell.

CWCSC's focus is to provide support for Solano County communities to take action based on local needs. Coalition members further extend their impact by providing information sessions to a broad array of agencies, organizations and individuals throughout the county. CWCSC helped Napa County to start its own Children and Weight coalition. CWCSC members have provided training sessions for South Carolina and Ohio Cooperative Extension advisors, served as consultants for similar coalitions across the nation and in Canada, and extended information about the CWCSC at regional sessions and three national health-promotion conferences.

\section{Get Moving Kern}

Kern County's first Childhood Overweight Coalition meeting was

\section{By pooling resources,} coalition members have the opportunity to reach a much larger audience with programs that have greater impact on lifestyle behaviors.

\begin{abstract}
Throughout California, community coalitions have been formed to develop comprehensive approaches for combating childhood overweight. The Shasta County Coalition for Activity and Nutrition (Shasta CAN) hosts an annual Lean-N-Green Day to promote health and fitness, during which kids played a "My Pyramid" nutrition education game.
\end{abstract}

held in Bakersfield in February 2002. Invitations announcing the first two meetings were mailed to 600 Kern County individuals, agencies, schools, health insurance companies, community health organizations, the agriculture community and other organizations. These initial meetings were attended by 30 to 40 people. From February 2002 to October 2004, the meetings were co-chaired by the county's UC Cooperative Extension nutrition, family and consumer advisor and a health educator from the Kern County Department of Public Health.

The Children and Weight: What Communities Can Do curriculum was used to guide the first four meetings. A "Community Food and Fun Day" was the first project the group pursued, but lack of support by members of the coalition to plan the event doomed it to failure. In a festival-type setting, it was planned to have people participate in cooking demonstrations; taste healthy, reduced-fat foods; and try out low-cost, family-centered physical activities. The coalition regrouped and sponsored three community information meetings and workshops for the public, physicians and health professionals.

During this time, the city of Bakersfield was in the midst of a strategic planning process (called Bakersfield Visions 2020) that included a task force 
on obesity. The Childhood Overweight Coalition merged with this task force in January 2005 to form "Get Moving Kern." This new coalition includes about 15 members, primarily from healthrelated fields, and meets monthly. Get Moving Kern focuses on increasing physical activity and spreading the message of consuming more fruits and vegetables. They have developed a logo, launched a Web site and are currently looking for grant opportunities.

UC Cooperative Extension in Kern County continues to be a member of the obesity coalition, and new stakeholders have joined, including the physical education department of California State University, Bakersfield. Unfortunately, the local farming community did not respond to the Childhood Overweight Coalition's invitation to participate in the coalition meetings; they are an important missing link in the planning process. Kern County is one of the largest fruit- and vegetable-producing counties in the United States, and farmers are an important source for the donations of fresh fruits and vegetables for public events, which have been successfully used to reach the public with healthy-eating messages.

Get Moving Kern and other childhood obesity coalitions need to do more aggressive outreach and education to attract missing stakeholders such as farmers, community members, schools, restaurants, and individuals and companies involved in sports and physical activity. These groups would bring a different perspective to the planning process.

\section{Team approaches to health issues}

As these case studies demonstrate, the community coalition approach harnesses resources that are already available by drawing upon a diversity of community partners, their expertise and

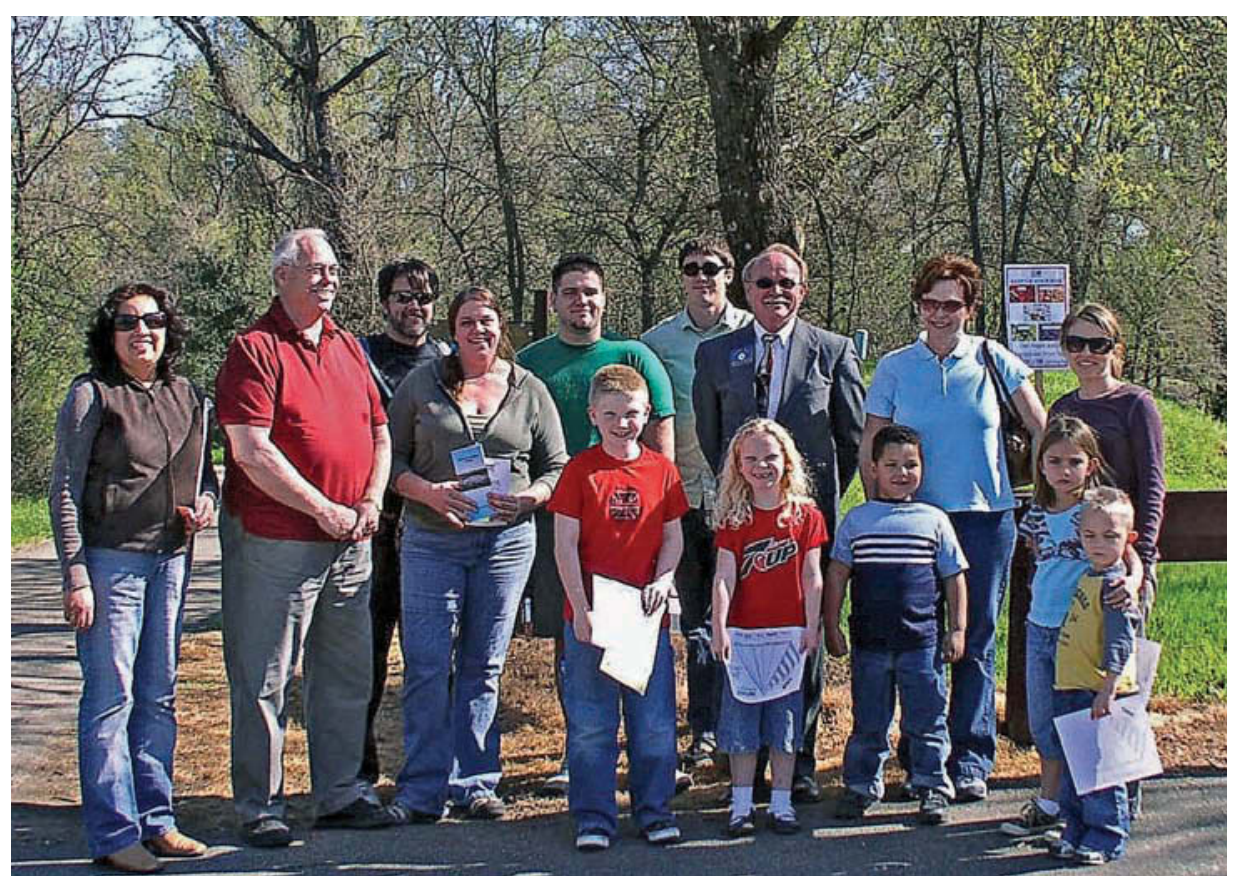

Community coalitions harness resources by drawing upon diverse partners and applying resources strategically. In Shasta County, Redding Mayor Dick Dickerson (second from left) and Anderson Mayor Keith Webster (third from right) are collaborating to promote better nutrition and physical activity countywide.

scopes of influence. These ingredients maximize the coalition's effectiveness and enhance the possibility of achieving its mission. The community coalitions we have worked with have increased awareness of childhood overweight as a potential health issue and improved the well-being of children and youth in these locales. The future holds great promise for coalitions to assist with this epidemic and encourage others to consider developing coalitions as a tool.

G.B. Espinosa-Hall is Program Manager, Shasta County Public Health, and was Nutrition, Family and Consumer Sciences Advisor, UC Cooperative Extension (UCCE), Shasta and Trinity counties; D. Metz is Nutrition, Family and Consumer Sciences Advisor, UCCE Yolo and Solano counties, and Yolo County Director; M. Johns is Nutrition, Family and Consumer Sciences Advisor, UCCE Kern County; D. Smith is Nutrition, Family and Consumer Sciences Advisor, UCCE Amador and Calaveras counties, and Amador County Director; P.B. Crawford is Adjunct Professor, Cooperative Extension Specialist and Co-Director, Center for Weight and Health, UC Berkeley; K. Siemering is Community Programs Coordinator, University of Wisconsin, Madison; and J. Ikeda is UCCE Nutrition Specialist Emeritus, UC Berkeley. Karen Varcoe, Consumer Economics Specialist, UC Riverside, served as Guest Associate Editor for this manuscript. The Food Stamp Nutrition Education program of USDA funded this project.

\section{References}

[AAHPERD] American Alliance for Health, Physical Education, Recreation and Dance. 2005. No Child Left Behind Background Paper, Leadership Development Conference, June 2005.

[CBO] Congressional Budget Office. 2004. S 2507 Child Nutrition and WIC Reauthorization Act of 2004. www.cbo.gov/ftpdoc.cfm?index $=5518$ \&type $=0$ \&sequence $=0$.

[CDC] Centers for Disease Control and Prevention. Kids Walk-to-School: Then and Now - Barrier and Solutions. www.cdc.gov/nccdphp/dnpa/kidswalk/then_and_now.htm (accessed Jan. 17, 2006).

Chavis DM. 2001. The paradoxes and promise of community coalitions. Am J Community Psychol 29(2):309-20.

Cohen L, Smith S. 1999. The Spectrum of Prevention: Developing a comprehensive approach to injury prevention. Injury Prev 5:203-7. www. preventioninstitute.org/spectrum_injury.html.

Fagot-Campagna A, Pettitt DJ, Engelgau MM, et al. 2000. Type 2 diabetes among North American children and adolescents: An epidemiologic review and a public health perspective. J Pediatrics 136:664-72.

Kant AK. 2003. Reported consumption of lownutrient density foods by American children and adolescents. Arch Pediatr Adolesc Med 157:789-96.

[NCHS] National Center for Health Statistics. 2007. Prevalence of Overweight Among Children and Adolescents: United States, 2003-2004. www.cdc.gov/nchs/products/pubs/pubd/hestats/ overweight/overwght_child_03.htm.

Roberts D, Foehr U. 2004 Kids and Media in America. Cambridge, MA: University Pr.

Troiano RP, Flegal KM. 1998. Overweight children and adolescents: Description, epidemiology, and demographics. Pediatrics 101:497-504.

Zakocs RC, Edwards EM. 2006. What explains community coalition effectiveness?: A review of the literature. Am J Prev Med 30:351-61. 